\title{
Test-specific manifestations of associative tolerance to the analgesic effects of morphine in the rat
}

\author{
ANTONIO CEPEDA-BENITO \\ Texas A\&M University, College Station, Texas \\ and \\ STEPHEN T. TIFFANY \\ Purdue University, West Lafayette, Indiana
}

\begin{abstract}
The acquisition of associative tolerance to the analgesic effects of morphine as assessed on the hotplate test was investigated in two experiments. Associative contingencies were manipulated by giving rats eight moderately high morphine doses $(20 \mathrm{mg} / \mathrm{kg}$ ) either paired or unpaired with a distinctive context at a 96-h interdose interval. Tolerance was evaluated as shifts in dose-response curves of morphine-experienced relative to morphine-naive animals tested in the distinctive context. Experiment 1, in which independent groups of animals were tested with hot-plate temperatures of $50^{\circ} \mathrm{C}(N=302)$ and $54^{\circ} \mathrm{C}(N=175)$, produced no evidence of context-specific tolerance to morphine. Experiment $2(N=$ 200) evaluated the effect of contextual contingencies of drug delivery on the development of morphine tolerance in animals tested on either the hot-plate or the tailflick test. As found in Experiment 1, animals tested on the hot plate showed no context-specific tolerance, whereas animals tested on the tailflick displayed pronounced associative-tolerance effects. The data suggest that the hot plate, as opposed to other tests of analgesia, does not provide a sensitive measure of associative morphine tolerance.
\end{abstract}

There is considerable evidence that many examples of drug tolerance represent the operation of classical conditioning (see review by Young \& Goudie, 1995). Most of the support for this assertion comes from investigations of tolerance to the analgesic effects of morphine. In these studies, animals receiving morphine explicitly paired with a distinctive test context have been more tolerant to morphine's analgesic effects than animals receiving the same drug exposure regimen in an environment other than the distinctive context (e.g., Cepeda-Benito \& Tiffany, 1992, 1995, in press; Dafters \& Odber, 1989; Dafters, Odber, \& Miller, 1988; Krank, Hinson, \& Siegel, 1981; Siegel, 1975, 1977; Tiffany \& Baker, 1981; Tiffany, Drobes, \& Cepeda-Benito, 1992; Tiffany \& Maude-Griffin, 1988; Tiffany, Maude-Griffin, \& Drobes, 1991). The conditioning explanation for these findings is that the distinctive context has become a conditioned stimulus (CS) that elicits associative tolerance effects (Baker \& Tiffany, 1985; Poulos \& Cappell, 1991; Siegel, 1975).

The early demonstrations of context-specific tolerance to the analgesic effects of morphine were conducted with the hot plate (e.g., Adams, Yeh, Woods, \& Mitchell, 1969), and much of the initial research purporting to show as-

This research was supported by Research Grant R01 DA04050 from the National Institute on Drug Abuse awarded to S.T.T. We thank Peggy Treece for her help in manuscript preparation. Correspondence concerning this article should be addressed to S. T. Tiffany, Department of Psychological Sciences, 1364 Psychology Building, Purdue University, West Lafayette, IN 47907-1364 (e-mail: tiffany@psych.purdue.edu). sociative morphine tolerance was done with this test (e.g., Siegel, 1975, 1976, 1977). The hot-plate test, which measures the latency of a rat to lick a paw or jump when placed on a hot surface, provides a sensitive, dose-dependent assessment of morphine's analgesic effects (Jóhannesson \& Woods, 1964). With few exceptions (e.g., Krank, 1987; Siegel, Hinson, \& Krank, 1978), most associative tolerance research with the hot plate has allowed animals to practice the test response each time that morphine is administered in the presence of distinctive cues (e.g., Dafters \& Odber, 1989; Dafters et al., 1988; Siegel, 1975, 1976, 1977). A consideration of the conditioning procedures used in many of these hot-plate studies has led to suggestions that context-specific tolerance is not due to classical conditioning but may have been acquired through instrumental contingencies (Hayes \& Mayer, 1978) or may reflect some stress phenomenon that mimics tolerance acquisition (e.g., Bardo \& Hughes, 1979; Rochford \& Stewart, 1987; Westbrook \& Greeley, 1992). For example, animals permitted to practice a task while drugged can develop more tolerance to the disruptive effects of that drug on performance than can animals given as much drug but no opportunity for drugged practice (see reviews by Goudie \& Demellweek, 1986; Tiffany \& Baker, 1986; Wolgin, 1989; Young \& Goudie, 1995). It has been proposed that this effect of practice during intoxication represents the operation of instrumental conditioning resulting in the learning of specific compensations for druginduced disruptions in performance (see, e.g., Chen, 1968; Schuster, Dockens, \& Woods, 1966; Wolgin, 1989). 
The few studies that have not allowed practice on the hot plate over the course of conditioning did not expose animals to a nonfunctional hot plate at each conditioning session (e.g., Siegel et al., 1978; Siegel, Hinson, \& Krank, 1981) or did not include control groups receiving comparable exposure to the test environment prior to assessment of tolerance (Siegel, 1975; Experiment 1A). Consequently, the results of these studies may have been confounded by novelty or stress-induced analgesia (Bardo \& Hughes, 1979; Rochford \& Stewart, 1987; Sherman, 1979). This hypothesis was supported in an investigation by Westbrook and Greeley (1992), in which rats that were habituated to an unheated plate over the course of conditioning developed tolerance to morphine analgesia but displayed no evidence of context-specific tolerance. Several features of that research, however, precluded the direct evaluation of conditioned-tolerance effects. Tolerance was assayed with a single-test dose, and the detection of context-specific tolerance might have been obscured by floor effects. Moreover, the conditioning procedures may have allowed animals to use handling and injection cues to predict morphine delivery. Such cues could have overshadowed the associative contribution of contextual stimuli in the control of learned tolerance effects (CepedaBenito \& Tiffany, 1995; Dafters \& Bach, 1985).

Research done with tests of analgesia other than the hot plate has provided examples of classically conditioned tolerance not contaminated by intoxicated practice or stress effects. For example, we have conducted numerous investigations of associative tolerance to the analgesic effects of morphine using the tailflick device, which measures the latency for a rat to withdraw its tail from a radiant heat source (Cepeda-Benito \& Tiffany, 1992, 1995, in press; Tiffany et al., 1992; Tiffany \& Maude-Griffin, 1988; Tiffany et al., 1991). In these studies, animals were exposed to a nonfunctional tailflick device over the course of conditioning and were not assessed until the tolerance test session. These procedures eliminate the opportunity for practice during intoxication and minimize novelty effects on the tolerance test. Further, tolerance in these investigations was evaluated as shifts in dose-response curves to the right. Dose-response curve methodology provides a sensitive index of tolerance development that corresponds to the pharmacological definition of drug tolerance (Kalant, LeBlanc, \& Gibbons, 1971) and is not subject to the limitations imposed by the use of a single test dose. The results of these studies show consistently that tolerance to the analgesic effects of morphine, as measured by rightward shifts in dose-response curves, can readily come under the associative control of drugpaired contexts.

\section{EXPERIMENT 1}

The present experiments were designed to determine whether procedures producing clear demonstrations of associative-tolerance effects on the tailflick test (e.g., Cepeda-Benito \& Tiffany, 1992; Tiffany et al., 1991) would yield similar evidence of classically conditioned tolerance on the hot plate. Rats were administered a series of moderately high morphine doses either paired or unpaired with a distinctive environmental context. A control group was given saline injections and a comparable amount of distinctive-context exposure over the course of conditioning. During each distinctive-context session, the animals were exposed to a nonfunctional hot plate. At the completion of conditioning, the animals were tested on the hot plate in the distinctive context. Dose-response curve methodology was used to evaluate the development of tolerance to the analgesic effects of morphine. Associative tolerance on the hot plate test should be manifest as a context-specific tolerance effect, with animals that had received morphine paired with the distinctive context displaying a greater rightward shift in their dose-response curve than that for animals that had received morphine unpaired with the distinctive context. Experiment 1 consisted of two independent attempts at obtaining context-specific morphine tolerance using a $50^{\circ} \mathrm{C}$ hot plate to test for morphine effects. Analyses revealed the same pattern of results regardless of whether the two studies were analyzed individually or combined into a single data set. This report will present the analyses from the combined data set.

\section{Method}

Subjects. The subjects were 302 experimentally naive, male Holtzman rats, approximately 100 days old on their tolerance test session. The rats were housed individually in wire mesh cages located in a colony room (on a 12:12-h light:dark schedule with lights on at $0600 \mathrm{~h}$ ) and maintained with continuous access to food and water in their home cages.

Drugs. The dose of morphine sulfate (expressed as the salt) used during the tolerance development phase was $20 \mathrm{mg} / \mathrm{kg}$. Tolerance test doses were $2.5,5,7.5,10,15$, and $20 \mathrm{mg} / \mathrm{kg}$ of morphine sulfate. The morphine was dissolved in saline with the overall salinity adjusted so that each dose was isotonic with physiological saline. Solutions were injected intraperitoneally in a volume of $1.25 \mathrm{ml} / \mathrm{kg}$.

Hot plate assessment. The hot plate (ITC, Model 39) consisted of a metal surface, thermostatically controlled to a constant temperature of $50^{\circ} \mathrm{C}$ (e.g., Bardo \& Hughes, 1978; Walter \& Riccio, 1983). Pilot work indicated that, at this temperature, the hot-plate test was more sensitive to small dose increments than at higher temperatures (see also O'Callaghan \& Holtzman, 1975; Walter \& Riccio, 1983). The rats were confined to the hot plate's surface by a clearlidded chamber $(30 \times 30 \times 30 \mathrm{~cm})$. Two observers timed each rat's latency to lick a hind paw or jump (see Krank, 1987). Animals that neither jumped nor licked a paw after $60 \mathrm{sec}$ were removed from the apparatus to prevent tissue damage.

Habituation. Prior to the start of conditioning, rats were weighed once daily for 3 days, then weighed twice daily for 3 days, and, finally, weighed and injected with saline twice daily for 8 days. The injections took place at 0900 and $1600 \mathrm{~h}$.

Tolerance development phase. During this phase, each rat was given eight injections paired with a distinctive context and eight injections in its home cage environment. The interval between context exposures was $96 \mathrm{~h}$, and home cage injections were administered $48 \mathrm{~h}$ after each distinctive context exposure. The distinctive context consisted of a dimly lit room with white noise $(75 \mathrm{~dB})$ played continuously over a loud speaker. The room was scented with pine air fresheners. The subjects were placed in in plastic boxes $(35 \times$ $31 \times 16 \mathrm{~cm}$ ) containing wood shavings and covered with wire mesh tops. The hot-plate device was also located in this room. The animals were carried from their home cage to the room serving as the 
distinctive context, injected with morphine or saline, and put in a plastic holding box. Each animal was placed on the unheated surface of the hot plate for $60 \mathrm{sec}$ at 30 and $60 \mathrm{~min}$ after its injection. The animal was returned to its home cage after the 60 -min mock hot-plate exposure. For the home cage injections, each rat was weighed and then injected with either morphine or saline. All home cage and distinctive-context procedures took place between 0730 and $1300 \mathrm{~h}$.

The animals were divided randomly into three conditioning groups. In the DC group $(n=109)$, each animal received morphine in the distinctive context during each conditioning session. Home cage injections consisted of saline for this group. The animals in the HC group ( $n=106)$ received saline injections paired with the distinctive context. The home cage injections for this group consisted of morphine. The saline control $(\mathrm{SC})$ animals $(n=87)$ were given saline injections in both environments.

Test session. The test session occurred in the distinctive context $96 \mathrm{~h}$ after the last distinctive-context exposure. The only difference between the two studies of Experiment 1 was in the selection of test doses for the development of dose-response curves. Whereas in one study the test doses were $2.5,5,10,15$, and $20 \mathrm{mg} / \mathrm{kg}$, in the other they were $2.5,5,7.5$, and $10 \mathrm{mg} / \mathrm{kg}$. In each study, each group was divided into four subgroups $(n=10-16)$, with each subgroup receiving a different test dose of morphine. After the studies were combined, the number of subjects per dose within each of the three treatment groups ranged from 10 to 16 rats for doses $7.5,15$, and $20 \mathrm{mg} / \mathrm{kg}$, and from 23 to 28 rats for doses $2.5,5$, and $10 \mathrm{mg} / \mathrm{kg}$. All animals received analgesia assessments, which were conducted in lieu of mock hot-plate trials, at 30 and 60 min after the injection.

Data analyses. Multiple regression analyses (Cohen \& Cohen, 1975) were performed on the 30-min data to compare the doseresponse curves of particular groups and group combinations using regression procedures described in Tiffany et al. (1991). The data from the 60 -min assessments, which revealed essentially the same pattern of results obtained with the 30 -min data, will not be reported here.

\section{Results and Discussion}

Results from animals tested on a $50^{\circ} \mathrm{C}$ hot plate (Figure 1) demonstrated the systematic pairing of the distinctive test context with drug delivery during conditioning did not produce context-specific tolerance effects. That is, the dose-response curve of DC animals was not significantly shifted to the right of $\mathrm{HC}$ animals $(F<1)$. However, both $\mathrm{DC}$ and $\mathrm{HC}$ animals produced dose- response curves shifted to the right of SC rats [s $R^{2}=.03, F(1,193)=$ $9.41, p<.001$, and $\mathrm{s} R^{2}=.02, F(1,190)=6.30, p<.005$, respectively]. The majority of studies purporting to demonstrate associative tolerance effects on the hot plate have used test temperatures higher than the $50^{\circ} \mathrm{C}$ used in the present experiment (e.g., Krank, 1987; Siegel, 1975, 1976, 1977; Siegel et al., 1978). Therefore, this experiment was replicated by using a $54^{\circ} \mathrm{C}$ hot-plate assessment to determine whether the failure to obtain context-specific tolerance on the hot plate was a function of the testing temperature. This study $(N=175)$ produced no evidence of context-specific morphine tolerance.

The absence of a context-specific tolerance effect in these experiments was unexpected, because we used the same experimental procedures that so consistently produce strong associative tolerance with the tailflick test (e.g., Carter \& Tiffany, 1996; Cepeda-Benito \& Tiffany,

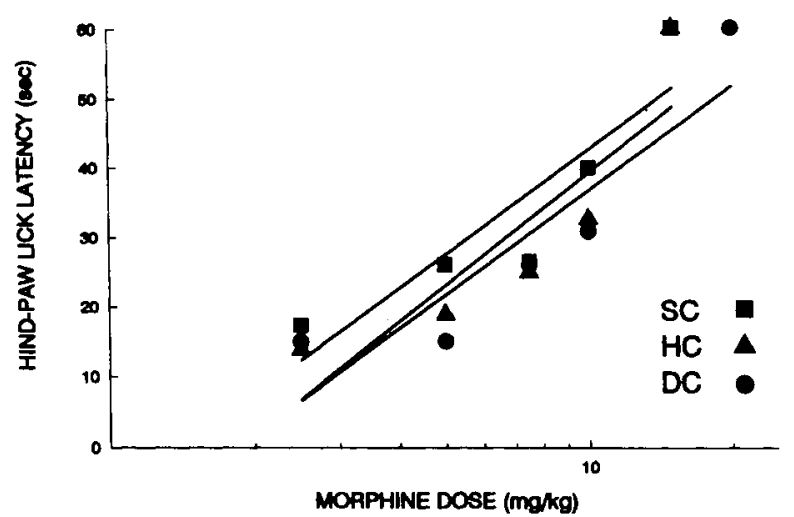

Figure 1. Mean hot-plate latency on the test session for each test dose as a function of morphine dose, depicted on a log scale, for each of the treatment groups. The straight lines for each group represent the best fitting line calculated with hot-plate latency regressed on log dose of morphine. These data are from the hot-plate test conducted $30 \mathrm{~min}$ after morphine administration. DC, morphine paired with the distinctive context; HC, morphine unpaired with the distinctive context; SC, saline controls.

1992, 1995, in press; Cox \& Tiffany, in press; Tiffany et al., 1992; Tiffany \& Maude-Griffin, 1988; Tiffany et al., 1991). This discrepancy in results across these two methods of testing can be accommodated by either of two explanations. First, to the extent that homeostatic perturbations are critical to the development of drug tolerance (Poulos \& Cappell, 1991), the behavioral consequences of exposure to a nonfunctional hot plate might not be as homeostatically disruptive as exposure to a nonfunctional tailflick. In particular, mock tailflick exposures entail multiple episodes of animals' being held on the tailflick device. In contrast, during mock hot-plate exposures, animals are confined in a chamber but are not restrained. Consequently, the hot-plate procedures might not be particularly supportive of tolerance development. Second, animals in the present experiments might have developed associative tolerance, but this effect was not manifested on the hot-plate test.

\section{EXPERIMENT 2}

This experiment was designed to test whether exposing animals to a nonfunctional tailflick during distinctive-context exposures would facilitate the expression of contextual morphine tolerance on the hot-plate test. Rats were treated as in Experiment 1, but with two exceptions: (1) they were exposed to a nonfunctional tailflick apparatus immediately following each exposure to the unheated hot plate; and (2) during the test session, separate groups were tested on either a hot plate or a tailflick apparatus. If context-specific tolerance arises as a function of the homeostatic disturbance induced by the mock tailflick procedures, exposure to these procedures should yield evidence of associative tolerance on both the hotplate and tailflick tests. Alternatively, evidence of context- 
specific tolerance on the tailflick but not the hot-plate test would suggest that associative tolerance to the analgesic effects of morphine is somewhat test specific.

\section{Method}

Subjects. The subjects, 200 experimentally naive male Holtzman rats, were maintained as described in Experiment 1.

Analgesia assessment. Analgesia was assessed by the tailflick and the hot-plate methods. The tailflick measured the latency for the rat to remove its tail from the radiant heat generated by a prefocused 125-W projector bulb (see, e.g., Cepeda-Benito \& Tiffany, 1992). During a tailflick test, the experimenter held the rat on a flat surface, and the rat's tail was placed in a grooved acrylic plate under the heat source. Each assessment consisted of the average of three consecutive trials. The intensity of the heat source was adjusted such that nondrugged animals flicked at approximately $3.5 \mathrm{sec}$, and a $15-\mathrm{sec}$ limit was used for each trial. The hot-plate procedures were identical to those employed in Experiment 1.

Habituation and tolerance development. The habituation and tolerance development procedures were identical to those used in Experiment 1, except for an addition of mock tailflick procedures during each distinctive-context session. Immediately after each mock hot-plate exposure, each rat was given mock tailflick trials, with the radiant heat source activated but not directed on the rat's tail.

Test session. After tolerance development, DC $(n=68), \mathrm{HC}$ $(n=66)$, and SC $(n=66)$ rats were divided randomly into hotplate and tailflick test conditions. The test session occurred in the distinctive context $96 \mathrm{~h}$ after the last distinctive-context exposure. In order to construct dose-response curves, each group was divided into four subgroups ( $n=8-9$ ), with each subgroup receiving a different test dose of morphine (range $=2-32 \mathrm{mg} / \mathrm{kg}$ ). Hot-plate animals received hot-plate analgesia assessments, which were conducted in lieu of mock hot-plate trials at 30 and 60 min after the injection. After each hot-plate assessment, each rat was given mock tailflick trials as during the tolerance development phase. Tailflick animals received tailflick analgesia assessments, which were conducted in lieu of mock tailflick trials at 31 and $61 \mathrm{~min}$ after the injection. Prior to each tailflick assessment, each rat received a $60-\mathrm{sec}$ exposure to an unheated plate as during the tolerance development phase.

\section{Results and Discussion}

Hot plate. Animals tested on the hot plate (Figure 2A) provided no evidence that the systematic pairing of the distinctive test context with drug delivery during conditioning produced context-specific tolerance effects. That is, the dose-response curves of DC and $\mathrm{HC}$ animals did not differ significantly $(F<1)$. However, both $\mathrm{DC}$ and $\mathrm{HC}$ animals produced dose-response curves that were shifted to the right of SC rats $\left[\mathrm{s} R^{2}=.13, F(1,62)=\right.$ $26.46, p<.001$, and $s R^{2}=.10, F(1,62)=22.01, p<.001$, respectively]. These results suggest that exposure of animals to the mock tailflick procedures during conditioning did not promote the development of context-specific tolerance on the hot-plate test.

Tailflick. Animals tested on the tailflick (Figure 2B) demonstrated the pairing of the distinctive test context with morphine administration during conditioning produced strong context-specific tolerance; the dose-response curve of DC animals was shifted significantly to the right of $\mathrm{HC}$ animals [s $\left.R^{2}=.13, F(1,63)=21.04, p<.001\right]$. In turn, $\mathrm{HC}$ animals produced dose-response curves shifted significantly to the right of $\mathrm{SC}$ rats $\left[\mathrm{s} R^{2}=.03, F(1,61)=\right.$
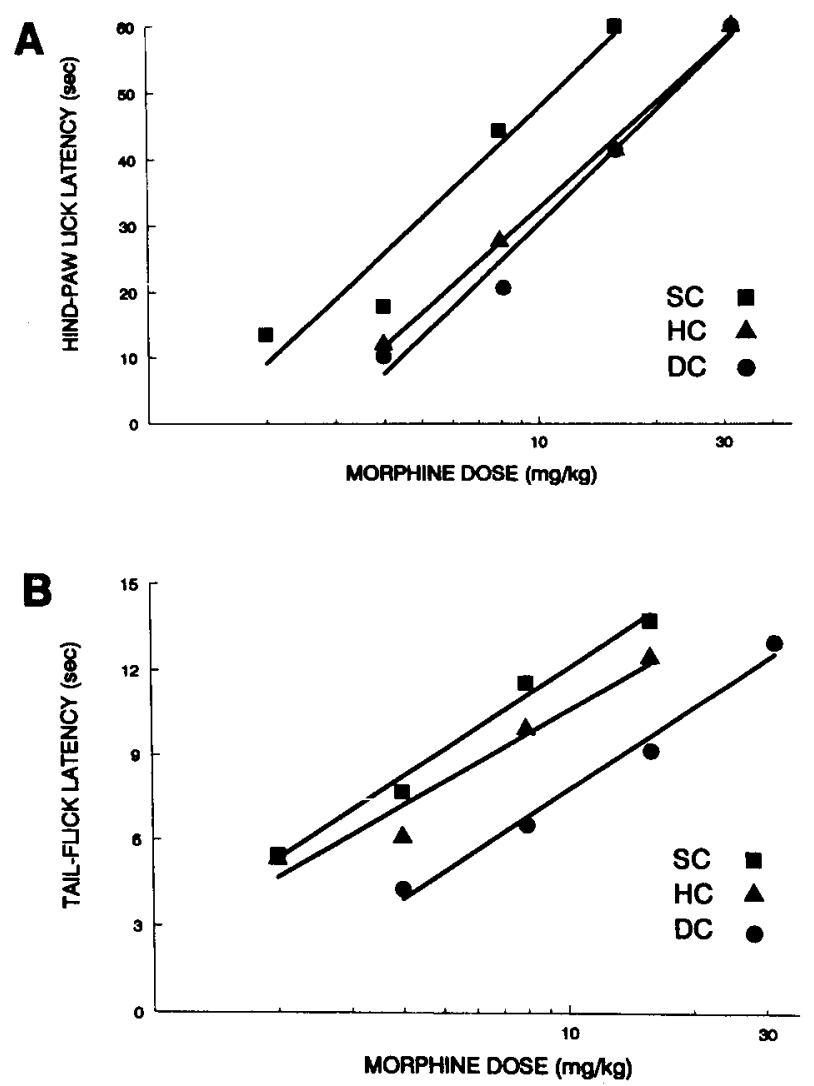

Figure 2. Mean hot-plate latency (A) and tailflick latency (B) on the test session for each test dose as a function of morphine dose, depicted on a log scale, for each of the treatment groups. The straight lines for each group represent the best fitting line calculated with latency regressed on log dose of morphine. These data are from tests conducted $30 \mathrm{~min}$ (hot plate) or $\mathbf{3 1} \mathrm{min}$ (tailflick) after morphine administration. DC, morphine paired with the distinctive context; HC, morphine unpaired with the distinctive context; SC, saline controls.

$7.01, p<.025]$. These data show that animals exposed to both mock hot-plate and mock tailflick procedures over the course of conditioning did acquire associative tolerance as assayed on the tailflick test. This demonstration of associative tolerance replicates the outcome of numerous previous investigations from our laboratory using the tailflick test for assessment of analgesia (Carter \& Tiffany, 1996; Cepeda-Benito \& Tiffany, 1992, 1995, in press; Cox \& Tiffany, in press; Tiffany et al., 1992; Tiffany \& Maude-Griffin, 1988; Tiffany et al., 1991).

\section{GENERAL DISCUSSION}

The present research produced no evidence of contextspecific tolerance to the analgesic effects of morphine assessed on the hot-plate test. The failure to obtain this effect occurred despite the evaluation of two hot-plate test temperatures, large numbers of subjects, and the use of dose-response curve methodology for the assessment of tolerance. Moreover, our conditioning procedures 
clearly supported the development of associative effects, because animals tested on the tailflick in Experiment 2 displayed pronounced context-specific tolerance.

Observations of associative tolerance to the analgesic effects of morphine have not been restricted to the tailflick test; similar context-specific effects have been obtained in research done with the flinch/jump, paw-pressure withdrawal, and tailshock vocalization tests of analgesia (Tiffany \& Baker, 1981; Tiffany \& Cepeda-Benito, 1994; Tiffany, Petrie, Baker, \& Dahl, 1983). In all these studies, conditioning procedures were similar to those employed in the present research, which minimized the influence of instrumental conditioning and stress responses in the production of context-specific tolerance. These previous findings, in combination with the present data, support the validity of an associative interpretation of context-specific tolerance across a variety of tests of analgesia other than the hot plate.

It is noteworthy that controversies regarding the contribution of associative processes to morphine tolerance have been derived principally from research done with the hot-plate test (e.g., Bardo \& Hughes, 1979; Rochford \& Stewart, 1987; Sherman, 1979; Sherman, Proctor, \& Strub, 1982; Westbrook \& Greeley, 1992). These investigations have demonstrated that some examples of context-specific morphine tolerance may represent stress effects and not classically conditioned tolerance. Others have suggested that some examples of context-specific tolerance on the hot plate are due to instrumental learning as a consequence of repeated practice of the test response (Hayes \& Mayer, 1978; Tiffany et al., 1991). Our findings are compatible with the possibility that previous exhibitions of associative tolerance using the hot-plate test might be attributable to the operation of stress responses or instrumental conditioning. When these confounding factors are minimized, as in the present research, the hot-plate test does not seem to yield a particularly sensitive assessment of associative tolerance effects.

The data provide few clues as to why the tailflick test consistently shows that drug-paired contexts can exert strong associative control over tolerance, whereas the hot plate does not. Some of the differential sensitivity of these two tests to associative tolerance may reside in the neurophysiological organization of the nociceptive responses and/or morphine-induced analgesia generated by each test. The hot-plate response is organized primarily at supraspinal levels, whereas the tailflick reflex is spinally mediated (see, e.g., Jensen \& Yaksh, 1986). Moreover, morphine analgesia on the tailflick test represents the activation of pain-inhibitory mechanisms at both spinal and supraspinal sites (e.g., Jensen \& Yaksh, 1986; Sinclair, Main, \& Lo, 1988). In contrast, morphine analgesia on the hot plate appears to arise primarily from supraspinal sites of action (Jensen \& Yaksh, 1986). Consequently, it is possible that morphine tolerance mechanisms supported by associative processes may operate at sites involved in tailflick but not hot-plate analgesia.

Morphine-experienced animals displayed some degree of tolerance across all the hot-plate assessments con- ducted in the present experiments. The extent to which this represented an effect arising solely from drug exposure (i.e., nonassociative tolerance) cannot be determined from these data. Research with the tailflick test suggests that the relatively long interdose interval would not be particularly supportive of the development of nonassociative tolerance effects (Tiffany et al., 1992; Tiffany et al., 1991). Nevertheless, the hot-plate test might detect forms of nonassociative tolerance not evident on the tailflick test (Sribanditmongkol, Sheu, \& Tejwani, 1994).

Alternatively, tolerance on the hot-plate test may have represented an associative effect controlled, not by the distinctive context, but by handling and injection cues that accompanied drug delivery. We have applied this explanation to HC tolerance effects obtained on the tailflick in studies in which long interdose intervals were used for conditioning (Cepeda-Benito \& Tiffany, 1992; Tiffany et al., 1991). For example, the tolerance displayed by $\mathrm{HC}$ animals tested on the tailflick in Experiment 2 likely represents such a phenomenon (Cepeda-Benito \& Tiffany, 1995). That is, despite extensive habituation of animals to the injection ritual prior to conditioning and the incorporation of numerous saline injections over the course of conditioning, injection cues may support a modest degree of associative tolerance in $\mathrm{HC}$ animals tested on the tailflick. Similarly, it might be argued that all of the tolerance observed on the hot plate was controlled associatively by injection cues. However, this hypothesis appears, a priori, to be questionable, since there is no empirical or theoretical basis for supposing that the hot plate might reveal associative effects supported by incidental cues such as the injection ritual and yet be insensitive to associative tolerance controlled by the distinctive context. Research examining tolerance retention (Tiffany et al., 1992) and the impact of extinction procedures on tolerance (Cepeda-Benito \& Tiffany, 1995) could be used to evaluate the associative or nonassociative nature of this hot-plate tolerance.

\section{REFERENCES}

Adams, W. J., Yeh, S. Y., Woods, L. A., \& Mitchell, C. L. (1969). Drug-test interaction as a factor in the development of tolerance to the analgesic effect of morphine. Journal of Pharmacology \& Experimental Therapeutics, 168, 251-257.

BAKER, T. B., \& TIFfANY, S. T. (1985). Morphine tolerance as habituation. Psychological Review, 92, 78-108.

Bardo, M. T., \& Hughes, R. W. (1979). Exposure to a nonfunctional hotplate as a factor in the assessment of morphine-induced analgesia and analgesic tolerance in rats. Pharmacology. Biochemistry \& $\mathrm{Be}$ havior, 10, 481-485.

CARTER, B. L., \& TifFANy, S. T. (1996). Cross-tolerance of associative and nonassociative morphine tolerance in the rat with $\mathrm{mu}-$ and kappaspecific opioids. Psychopharmacology, 123, 289-296.

Cepeda-Benito, A., \& Tiffany, S. T. (1992). Effect of the number of conditioning sessions on the development of associative tolerance to morphine. Psychopharmacology, 109, 172-176.

Cepeda-Benito, A., \& Tiffany, S. T. (1995). Role of drug-administration cues in the associative control of morphine tolerance in the rat. Psychopharmacology, 122, 312-316.

Cepeda-Benito, A., \& Tiffany, S. T. (in press). Unsignaled morphine delivery does not disrupt the development of associative morphine tolerance in the rat. Pharmacology, Biochemistry \& Behavior. 
CHEN, C. S. (1968). A study of the alcohol-tolerance effect and an introduction of a new behavioral technique. Psychopharmacologia, 12, 443-440.

COHEN, J., \& CoHEN, P. (1975). Applied multiple regression/correlational analysis for the behavioral sciences. Hillsdale, NJ: Erlbaum.

CoX, L. S., \& TifFANY, S. T. (in press). Associative and nonassociative tolerance to morphine in the rat: Effects of dose and interdose interval. Pharmacology, Biochemistry \& Behavior.

DAFTERS, R., \& BACH, L. (1985). Absence of environment-specificity in morphine tolerance acquired in nondistinctive environments: Habituation or stimulus overshadowing? Psychopharmacology, 87, 101-106.

Dafters, R., \& OdBer, J. (1989). Effects of dose, interdose interval, and drug-signal parameters on morphine analgesic tolerance: Implications for current theories of tolerance. Behavioral Neuroscience, 103, 1082-1090.

Dafters, R. I., Odber, J., \& Miller, J. (1988). Associative and nonassociative tolerance to morphine: Support for a dual-process habituation model. Life Sciences, 42, 1897-1906.

Goudie, A. J., \& DemellweEk, C. (1986). Conditioning factors in drug tolerance. In S. R. Goldberg \& I. P. Stolerman (Eds.), Behavioral analysis of drug dependence (pp. 225-285). New York: Academic Press.

HAYES, R. L., \& MAYER, D. J. (1978). Morphine tolerance: Is there evidence for a conditioning model? Science, 200, 343-344.

JENSEN, T. S., \& YAKSH, T. L. (1986). Comparison of antinociceptive action of morphine in the periaqueductal gray, medial and paramedial medulla in rat. Brain Research, 363, 99-113.

JóHANnesson, T., \& WoOds, L. A. (1964). Analgesic action and brain and plasma levels of morphine and codeine in morphine tolerant, codeine tolerant and non-tolerant rats. Acta Pharmacologica et Toxicologica, 21, 381-396.

Kalant, H., LeBlanc, A. E., \& Gibiins, R. J. (1971). Tolerance to, and dependence on, some nonopiate psychotropic drugs. Pharmacological Reviews, 23, 135-191.

KraNK, M. D. (1987). Conditioned hyperalgesia depends on the pain sensitivity measure. Behavioral Neuroscience, 101, 854-857.

Krank, M. D., Hinson, R. E., \& Siegel, S. (1981). Conditioned hyperalgesia is elicited by environmental signals of morphine. Behavioral \& Neural Biology, 32, 148-157.

O'Callaghan, J. P., \& Holtzman, S. G. (1975). Quantification of the analgesic activity of narcotic antagonists by a modified hot-plate procedure. Journal of Pharmacology \& Experimental Therapeutics, 192, 497-505.

Poulos, C. X., \& CAPpell, H. (1991). Homeostatic theory of drug tolerance: A general model of physiological adaptation. Psychological Review, 98, 390-408.

ROCHFORD, J., \& STEWART, J. (1987). Morphine attenuation of conditioned autoanalgesia: Implications for theories of situation-specific tolerance to morphine analgesia. Behavioral Neuroscience, 101, 690-700.

Schuster, C. R., Dockens, W. S., \& Woods, J. H. (1966). Behavioral variables affecting the development of amphetamine tolerance. $P s y$ chopharmacologia, 9, 170-182.

Sherman, J. E. (1979). The effects of conditioning and novelty on the rats' analgesic and pyretic responses to morphine. Learning \& Motivation, 10, 381-418.

Sherman, J. E., Proctor, C., \& Strub, H. (1982). Prior hotplate exposure enhances morphine analgesia in tolerant and drug-naive rats. Pharmacology, Biochemistry \& Behavior, 17, 229-232.

SIEGEL, S. (1975). Evidence from rats that morphine tolerance is a learned response. Journal of Comparative \& Physiological Psychology, 89, 498-506.
SIEGEL, S. (1976). Morphine analgesic tolerance: Its situation specificity supports a Pavlovian conditioning model. Science, 193, 323-325.

SIEGEL, S. (1977). Morphine tolerance acquisition as an associative process. Journal of Experimental Psychology: Animal Behavior Processes, 3, 1-13.

Siegel, S., Hinson, R. E., \& KRANK, M. D. (1978). The role of predrug signals in morphine analgesic tolerance: Support for a Pavlovian conditioning model of tolerance. Journal of Experimental Psychology: Animal Behavior Processes, 4, 188-196.

SiegEl, S., Hinson, R. E., \& KRANK, M. D. (1981). Morphine-induced attenuation of morphine tolerance. Science, 212, 1533-1534.

Sinclair, J. G., MaIN, C. D., \& Lo, G. F. (1988). Spinal vs. supraspinal actions of morphine on the rat tail-flick reflex. Pain, 33, 357-362.

Sribanditmongkol, P., Sheu, M. J., \& Tejwani, G. A. (1994). Inhibition of morphine tolerance and dependence by diazepam and its relation to the CNS met-enkephalin levels. Brain Research, 645, 1-12.

TIFfANY, S. T., \& BAKER, T. B. (1981). Morphine tolerance in rats: Congruence with a Pavlovian paradigm. Journal of Comparative \& Physiological Psychology, 95, 747-762.

TiffanY, S. T., \& BaKer, T. B. (1986). Tolerance to alcohol: Psychological models and their application to alcoholism. Annals of Behavioral Medicine, 8, 7-12.

Tiffany, S. T., \& Cepeda-Benito, A. (1994). An examination of conditioned tolerance and potential compensatory responses on four assays of morphine analgesia. In Problems of drug dependence 1993 (National Institute on Drug Abuse Research Monograph No. 140, U.S. Department of Health and Human Services). Washington, DC: U.S. Government Printing Office.

Tiffany, S. T., Drobes, D. J., \& Cepeda-Benito, A. (1992). Contribution of associative and nonassociative processes to the development of morphine tolerance. Psychopharmacology, 109, 185-190.

TiffaNy, S. T., \& MAUDE-GrifFin, P. M. (1988). Tolerance to morphine in the rat: Associative and nonassociative effects. Behavioral Neuroscience, 102, 534-543.

Tiffany, S. T., Maude-Griffin, P. M., \& Drobes, D. J. (1991). The effect of interdose interval on the development of associative and nonassociative tolerance. Behavioral Neuroscience, 105, 49-61.

Tiffany, S. T., Petrie, E. C., Baker, T. B., \& Dahl, J. (1983). Conditioned morphine tolerance in the rat: Absence of a compensatory response and cross-tolerance with stress. Behavioral Neuroscience, 97 , 335-353.

WALTER, T. A., \& Riccio, D. C. (1983). Overshadowing effects in the stimulus control of morphine analgesic tolerance. Behavioral Neuroscience, 97, 658-662.

Westbrook, R. F., \& Greeley, J. D. (1992). Conditioned tolerance to morphine hypoalgesia: Compensatory hyperalgesia in the experimental group or conditioned hypoalgesia in the control group? Quarterly Journal of Experimental Psychology, 45B, 161-187.

WoLGIN, D. L. (1989). The role of instrumental learning in behavioral tolerance to drugs. In A. J. Goudie \& M. W. Emmit-Oglesby (Eds.), Psychoactive drugs: Tolerance and sensitization (pp. 17-114). Clifton, NJ: Humana Press.

YounG, A. M., \& GoudIE, A. J. (1995). Adaptive processes regulating tolerance to behavioral effects of drugs. In F. E. Bloom, D. J. Kupfer, B. S. Bunney, R. D. Ciaranello, K. L. Davis, G. F. Koob, et al. (Eds.), Psychopharmacology: The fourth generation of progress (pp. 657-811). New York: Raven Press.

(Manuscript received September 21, 1995; revision accepted for publication May 8,1996 .) 